\title{
Increasing the sustainability of alkali-activated binders: The use of sugar cane straw ash (SCSA)
}

\author{
J.C.B. Moraes ${ }^{a}$, M.M. Tashima ${ }^{a}$, J.L. Akasaki ${ }^{a}$, J.L.P. Melges ${ }^{a}$, J. Monzób ${ }^{b}$, M.V. Borrachero ${ }^{b}$, L. Soriano $^{b}$, \\ J. Payá ${ }^{\mathrm{b}, *}$ \\ ${ }^{a}$ UNESP - Grupo de Pesquisa MAC - Materiais Alternativos de Construção, Univ Estadual Paulista, Campus de Ilha Solteira, São Paulo, Brazil \\ ${ }^{\mathrm{b}}$ ICITECH - GIOUIMA Group - Grupo de Investigación en Ouímica de los Materiales de Construcción, Instituto de Ciencia y Tecnología del Hormigón, Universitat Politècnica \\ de Valencia, Valencia, Spain
}

\section{H I G H L I G H T S}

- Sugar cane straw ash (SCSA) was successfully used in alkali activated binders.

- New alkali-activated mixtures of SCSA and blastfurnace slag (BFS) were characterized.

- Total replacement of sodium silicate (SS) solution by SCSA enhanced sustainability.

- Good compressive mortar strength (37-48 MPa) was achieved without the use of SS.

- Replacement of $50 \%$ of BFS by SCSA showed an excellent mechanical behavior.

\section{A R T I C L E I N F O}

\section{Article history:}

Received 5 April 2016

Received in revised form 29 June 2016

Accepted 15 July 2016

Available online 25 July 2016

\section{Keywords:}

Silicates

Mechanical properties

Biomass

Renewable resources

Microstructural characterization
G R A P H I C A L A B S T R A C T

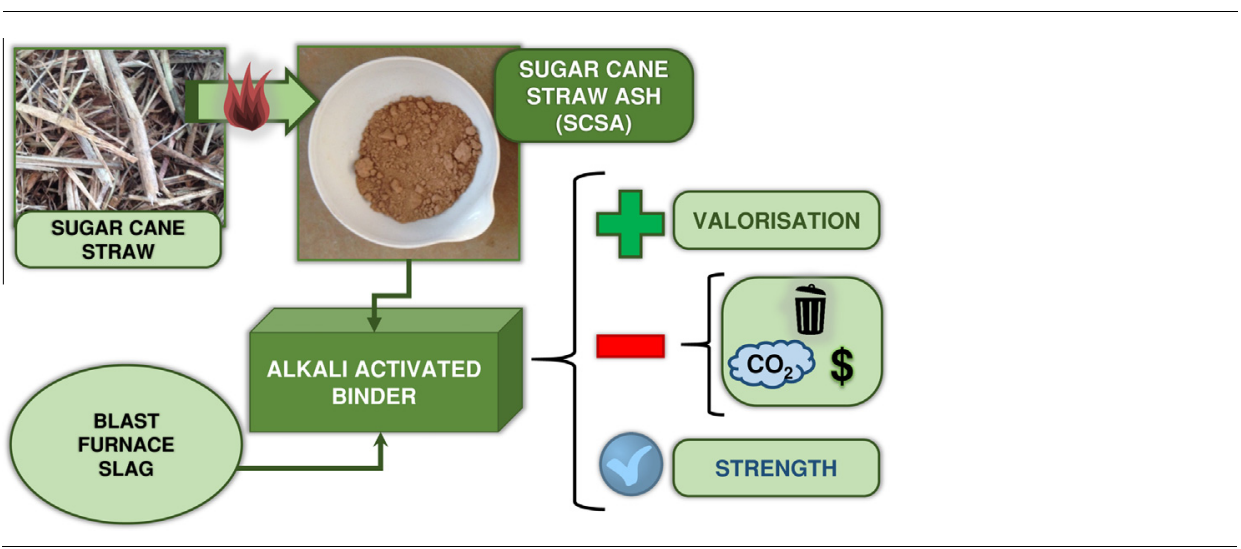

\begin{abstract}
A B S T R A C T
Alkali-activated binders are the new trend in building construction studies due their good mechanical properties and environmental advantages. These type of binders are obtained by a mixing of a solid precursor with an activating solution. In this study, the influence of sugar cane straw ash (SCSA) obtained from an auto-combustion process on blast-furnace slag (BFS) based alkali-activated binders was assessed as solid precursor. The studied proportions of BFS/SCSA were 100/0 (control), 85/15, 75/25, 67/33 and $50 / 50$ (by mass). Regarding to the activating solutions, three different mixtures were used: only $\mathrm{NaOH}$ $\left(8 \mathrm{~mol} \mathrm{~kg} \mathrm{Na}^{-1}\right)$ and two different combinations of $\mathrm{NaOH}$ with sodium silicate $\left(8 \mathrm{~mol} \mathrm{~kg} \mathrm{~kg}^{-1} \mathrm{Na}^{+}\right.$and $\mathrm{SiO}_{2} / \mathrm{Na}_{2} \mathrm{O}$ molar ratios of 0.50 and 0.75 ). The water/binder was maintained constant. To assess the influence of SCSA on BFS-alkali activated binders, mortars were evaluated in terms of compressive strength (3-90 days curing time at room temperature and 3 days at $65^{\circ} \mathrm{C}$ ); and pastes were studied to justify these results by means of thermogravimetric analysis (TGA), Fourier transform infrared spectroscopy (FTIR) and field emission scanning electron microscopy (FESEM). The presence of SCSA in the binder greatly improved the compressive strength when compared to the control BFS mortars, reaching values higher than $50 \mathrm{MPa}$ after 90 days. SCSA/BFS samples activated with sodium hydroxide yielded similar compressive strength values to those obtained for BFS mortars activated with sodium silicate. In the new binders, the partial replacement of BFS, the total replacement of sodium silicate solution and a new way of valorizing sugar cane straw enhanced sustainability.
\end{abstract}

(c) 2016 Elsevier Ltd. All rights reserved.

\footnotetext{
* Corresponding author.

E-mail address: jjpaya@cst.upv.es (J. Payá).
} 


\section{Introduction}

The development of sustainable construction materials is currently a new trend under investigation [1]. Alkali-activated (AA) binders are being researched as an alternative construction material to replace the use of Portland cement [2]. This type of binder is obtained when a highly alkali concentrated solution activates, due to the high $\mathrm{pH}$, a raw material (solid precursor), which can be metakaolin, fly ash, or blast furnace slag, among others [3-5]. The advantages of using AA binders instead of Portland cement based-mixtures are both technological and environmental. In some cases, the compressive strength and durability of these binders are higher, and they are more sustainable since they consume less energy, release less $\mathrm{CO}_{2}$ and the reuse of wastes [6-10]. Although AA binders present advantages in terms of sustainability compared to the ordinary Portland cement (OPC), it is possible to increase even more the benefits from this type of material.

Blast furnace slag (BFS), one of the most commonly used raw materials in the production of AA binders, as it presents many advantages in terms of its technological properties [11]. In recent years, blast furnace slag has been used in new AA systems with the addition of supplementary cementitious materials $[12,13]$. This has become an interesting method in the cement industry, taking into account that the cost of blast furnace slag is on the same order as that of Portland cement [14]. Thus, the design of new binary blast furnace slag-based systems is an interesting topic. In the preparation of AA binders, the alkaline solution is the most pollutant, expensive reagent and consumes the most energy. In general, this solution is composed of alkaline hydroxides and silicates; the latter emit high amounts of $\mathrm{CO}_{2}$ and have a high economic cost [15]. An alternative route is to reduce the use of alkaline silicates, replacing them with another more sustainable silicon source. As example, studies carried out on rice rusk ash (RHA) in the preparation of alkaline solutions showed similar mechanical properties for AA systems when compared to a control solution prepared with silicate-based chemical reagents [16].

This paper introduces a new raw material to produce an AA binder: sugar cane straw ash (SCSA). Brazil is the major sugar cane producer in the world with a production of 632 million tons in
2014-2015, which represents an increase of 64\% in the last ten years [17]. The straw represents $15-20 \%$ of the total mass of sugar cane produced; during harvesting, this straw is abandoned on the field, producing some environmental and technical problems [18]. This residue could be transformed into ash by burning because it is a valuable biomass, yielding sugar cane straw ash (SCSA). An interesting destination for SCSA is in the construction materials sector [19]. In this particular study, it will be assessed as a component in an AA binder system with blast furnace slag. The huge amount of this waste generated and previous studies on agroindustry residues in AA binders support this study $[20,21]$. SCSA from this study was obtained from an auto-combustion process of the straw. The ash was chemically and physically characterized, then assessed in BFS/SCSA systems (solid precursors) at these proportions: $100 / 0$ (control), 85/15, 75/25, 67/33 and 50/50. Three alkaline solutions were designed to activate the precursor: an $\mathrm{NaOH}$ solution and two $\mathrm{NaOH} /$ sodium silicate solutions. The $\mathrm{Na}^{+}$concentration in these solutions was held constant, whereas the $\mathrm{SiO}_{2} / \mathrm{Na}_{2} \mathrm{O}$ molar ratio (designated as $\varepsilon$ ) of the solution was varied to assess the influence of sodium silicate in the mixture. The compressive strength of the mortars, thermogravimetric analysis (TGA), Fourier transform infrared spectroscopy (FTIR), X-ray diffraction (XRD) and field emission scanning electron microscopy (FESEM) of the pastes were performed in order to assess the influence of SCSA on the BFSbased systems. The objective of this study was to valorize a waste from the agro-industry and reduce the use of a less sustainable material in the alkaline solution, i.e. sodium silicate. Additionally, savings in the consumption of BFS was an indirect goal.

\section{Materials and methods}

\subsection{Materials and equipment}

The sugar cane straw was received from a sugar cane plantation near of Ilha Solteira (São Paulo, Brazil). This material was burned by an autocombustion process, in which the maximum temperature reached was $700^{\circ} \mathrm{C}$. The residue from combustion was passed through sieves to remove the unburned matter, and the resulting ash was milled in a ball mill for $50 \mathrm{~min}$ in order to increase its reactivity. Blast furnace slag was obtained from Ribas do Rio Pardo (Mato Grosso do Sul, Brazil). Regarding the chemical composition, SCSA presented $\mathrm{SiO}_{2}, \mathrm{Al}_{2} \mathrm{O}_{3}, \mathrm{CaO}$ as main components. Table 1 summarizes the chemical composition of the solid

Table 1

Chemical composition of SCSA and BFS by weight percentage.

\begin{tabular}{|c|c|c|c|c|c|c|c|c|c|c|}
\hline Solid precursors & $\mathrm{SiO}_{2}$ & $\mathrm{Al}_{2} \mathrm{O}_{3}$ & $\mathrm{Fe}_{2} \mathrm{O}_{3}$ & $\mathrm{CaO}$ & $\mathrm{MgO}$ & $\mathrm{K}_{2} \mathrm{O}$ & $\mathrm{SO}_{3}$ & $\mathrm{Cl}$ & Others & LOI \\
\hline SCSA & 58.6 & 9.0 & 8.4 & 4.6 & 1.6 & 5.4 & 1.9 & 0.7 & 3.3 & 6.5 \\
\hline BFS & 33.0 & 11.5 & 0.6 & 43.5 & 7.3 & 0.4 & 1.9 & 0.1 & 1.6 & 0.1 \\
\hline
\end{tabular}

Table 2

Specimens' names, compressive strength of mortars (MPa) and their standard deviations.

\begin{tabular}{|c|c|c|c|c|c|c|c|}
\hline \multirow[t]{3}{*}{ Specimens' name } & \multirow[t]{3}{*}{$\varepsilon\left(\mathrm{SiO}_{2} / \mathrm{Na}_{2} \mathrm{O}\right)$} & \multirow[t]{3}{*}{ BFS/SCSA } & \multicolumn{5}{|c|}{ Curing time } \\
\hline & & & \multicolumn{4}{|l|}{$25^{\circ} \mathrm{C}$} & \multirow{2}{*}{$\begin{array}{l}65^{\circ} \mathrm{C} \\
3 \text { days }\end{array}$} \\
\hline & & & 3 days & 7 days & 28 days & 90 days & \\
\hline $\mathrm{N}-100 / 0$ & 0 & $100 / 0$ & $10.7 \pm 0.8$ & $15.5 \pm 0.2$ & $16.9 \pm 2.0$ & $27.3 \pm 0.8$ & $11.9 \pm 0.2$ \\
\hline $\mathrm{N}-85 / 15$ & & $85 / 15$ & $15.1 \pm 0.3$ & $25.1 \pm 0.5$ & $34.4 \pm 0.3$ & $37.9 \pm 3.2$ & $20.7 \pm 0.3$ \\
\hline $\mathrm{N}-75 / 25$ & & $75 / 25$ & $15.9 \pm 0.3$ & $24.4 \pm 1.9$ & $44.4 \pm 1.0$ & $44.5 \pm 2.0$ & $25.7 \pm 1.7$ \\
\hline $\mathrm{N}-67 / 33$ & & $67 / 33$ & $17.2 \pm 0.2$ & $23.9 \pm 2.3$ & $37.4 \pm 3.7$ & $43.6 \pm 2.2$ & $30.0 \pm 1.4$ \\
\hline $\mathrm{N}-50 / 50$ & & $50 / 50$ & $10.6 \pm 0.3$ & $20.6 \pm 0.1$ & $26.5 \pm 1.9$ & $47.9 \pm 1.2$ & $34.3 \pm 2.5$ \\
\hline SS50-100/0 & 0.50 & $100 / 0$ & $14.3 \pm 0.4$ & $25.6 \pm 0.5$ & $28.3 \pm 2.1$ & $51.2 \pm 1.4$ & $18.6 \pm 0.8$ \\
\hline SS50-85/15 & & $85 / 15$ & $15.8 \pm 0.4$ & $31.2 \pm 0.7$ & $47.2 \pm 2.2$ & $49.8 \pm 3.1$ & $31.8 \pm 1.1$ \\
\hline SS50-75/25 & & $75 / 25$ & $15.2 \pm 0.1$ & $25.6 \pm 1.1$ & $53.3 \pm 2.9$ & $49.2 \pm 0.7$ & $40.7 \pm 2.0$ \\
\hline SS50-67/33 & & $67 / 33$ & $13.2 \pm 0.2$ & $26.6 \pm 0.1$ & $38.1 \pm 3.3$ & $49.5 \pm 1.2$ & $40.4 \pm 1.6$ \\
\hline SS50-50/50 & & $50 / 50$ & $9.4 \pm 0.6$ & $18.4 \pm 1.7$ & $29.8 \pm 2.9$ & $50.8 \pm 2.8$ & $35.2 \pm 1.6$ \\
\hline SS75-100/0 & 0.75 & $100 / 0$ & $12.8 \pm 0.3$ & $26.7 \pm 0.6$ & $39.3 \pm 1.1$ & $51.5 \pm 4.1$ & $27.0 \pm 0.5$ \\
\hline SS75-85/15 & & $85 / 15$ & $6.1 \pm 0.2$ & $19.1 \pm 0.5$ & $44.4 \pm 2.9$ & $56.0 \pm 1.3$ & $27.3 \pm 0.6$ \\
\hline SS75-75/25 & & $75 / 25$ & $4.8 \pm 0.4$ & $14.0 \pm 0.5$ & $46.8 \pm 3.8$ & $51.4 \pm 3.1$ & $32.6 \pm 3.1$ \\
\hline
\end{tabular}


precursors (BFS and SCSA). . In their composition, the most interesting oxides for AA binders are the $\mathrm{SiO}_{2}, \mathrm{Al}_{2} \mathrm{O}_{3}$ and $\mathrm{CaO}$. AA binders based on BFS usually yields a (C,N)A-S-H gel, whose mechanical properties can be improved by the use of siliceous source. The SCSA is this source in the present case, and replacing partially the $\mathrm{BFS}$, can also improve the mechanical properties of the final AA binder [12]. In particle size studies, SCSA presented a mean particle diameter $\left(D_{\text {med }}\right)$ and median particle diameter $\left(D_{50}\right)$ of 18.1 and $10.6 \mu$ m respectively; for the BFS, these values were 27.5 and $21.4 \mu \mathrm{m}$, respectively.

Both sodium hydroxide pellets (solid, $98 \%$ purity) and sodium silicate (solid, 18 wt\% $\mathrm{Na}_{2} \mathrm{O}, 63 \mathrm{wt} \% \mathrm{SiO}_{2}$ ) were supplied by Dinâmica Química. In the preparation of solution, $\mathrm{NaOH}$ pellets were dissolved in water, producing an increase in the temperature of the solution. When sodium silicate was used, it was added to the hot $\mathrm{NaOH}$ solution in order to facilitate the dissolution rate. Prepared solutions were used when they reached room temperature.

Mortars were assessed by compressive strength in an EMIC Universal Machine with a $2000 \mathrm{kN}$ load limit at a loading rate of $0.5 \mathrm{MPa} / \mathrm{s}$. The compressive strength was an average of testing values on three cubic mortars of $50 \times 50 \times 50 \mathrm{~mm}^{3}$. Regarding to the pastes studies, the TGA equipment used was a Mettler-Toledo TGA 850 , where the specimen was heated in a $100 \mu \mathrm{L}$ sealed pin-holed aluminum crucible in the temperature range of $35-600{ }^{\circ} \mathrm{C}$, with a heating rate of $10^{\circ} \mathrm{C} \mathrm{min}^{-1}$ and $\mathrm{N}_{2}$ atmosphere ( $75 \mathrm{~mL} \mathrm{~min}^{-1}$ gas flow). FTIR was performed by a Bruker Tensor 27 in the range of 400 and $4000 \mathrm{~cm}^{-1}$. XRD patterns were obtained by a Bruker AXS D8 Advance with a voltage of $40 \mathrm{kV}$, current intensity of $20 \mathrm{~mA}$ and a Bragg's angle $(2 \theta)$ in the range of $5-70^{\circ}$. Finally, FESEM images were taken by a ZEISS Supra 55.

\subsection{Alkali activated binder dosage}

Five different BFS/SCSA proportions were assessed in this study: 100/0 (control), $85 / 15,75 / 25,67 / 33$ and 50/50 (by mass). For the alkaline activating solution, the $\mathrm{Na}^{+}$ concentration was held constant at $8 \mathrm{~mol} \mathrm{~kg}^{-1}$, whereas three $\mathrm{SiO}_{2} / \mathrm{Na}_{2} \mathrm{O}$ molar ratio of the solution $(\varepsilon)$ were assessed: 0 (only sodium hydroxide in the solution), 0.50 and 0.75 . The water/binder proportion (being binder the sum of BFS and SCSA) was 0.45 and, for mortars, the selected sand/binder ratio was 2.5 . Some mortars $(\varepsilon=0.75$ with $67 / 33$ and 50/50 ratios) presented rheological problems and they were not cast. Mortar specimens were assessed after $3\left(25^{\circ} \mathrm{C}\right.$ and $\left.65^{\circ} \mathrm{C}, \mathrm{RH}>95 \%\right), 7,28$ and 90 curing days (only $25^{\circ} \mathrm{C}, \mathrm{RH}>95 \%$ ). Paste samples were tested after 7, 28 and 90 curing days $\left(25^{\circ} \mathrm{C}, \mathrm{RH}>95 \%\right.$ ) for TGA and FTIR studies; for XRD and FESEM analysis, only samples with 28 days of curing time $\left(25^{\circ} \mathrm{C}, \mathrm{RH}>95 \%\right)$ were analyzed.

The nomenclature for AA binders studied in this paper is $x-y / z$, where the " $x$ " is related to the alkaline activating solution design and " $y / z$ " is the BFS/SCSA proportion in the mixture. The " $\mathrm{x}$ " can be N, SS50 and SS75, which are related the $\varepsilon$ value equals to 0 (only sodium hydroxide in the solution), 0.50 and 0.75 , respectively. Finally, the "y/z" values were $100 / 0,85 / 15,75 / 25,67 / 33$ and 50/50, as the already presented BFS/SCSA proportions. The specimen' names are provided in Table 2.

\section{Results and discussion}

The compressive strength $(\mathrm{Rc})$ values of the mortars are summarized in Table 2. The mean data were obtained from three $50 \times 50 \times 50 \mathrm{~mm}^{3}$ cubic specimens. In order to highlight the importance of SCSA in the mixture, a factor named $\gamma$ is proposed (Fig. 1), which represents the compressive strength ratio of a specimen with SCSA and its respective control $\left(\mathrm{Rc}_{\mathrm{SCSA}} / \mathrm{Rc}_{\text {control }}\right)$ under the same curing conditions. On one hand, it was observed that, for specimens with $\varepsilon=0$, SCSA had an important role in the development of compressive strength. These mixtures presented higher strengths than the control sample after 3 days of curing, with $\gamma$ factor values above 1.0 (Fig. 1a). On the other hand, for the samples activated with both sodium hydroxide and sodium silicate ( $\varepsilon=0.50$ and $\varepsilon=0.75$ ), the compressive strengths of the SCSA mortars were similar or lower than their respective controls, with $\gamma$ factor values lower than 1.0 after 3 days of curing (Fig. 1a). This behavior suggests that the presence of SCSA, when silicate anions are available in the prepared solution, does not provide any advantage, and produces a small delay in the cementing effect. This was especially marked for $\varepsilon=0.75$. Curiously, at this early age, the strength of SS75-100/0 (12.8 MPa) was surpassed by some SCSA containing mortars with $\varepsilon=0$ (e.g. 17.2 MPa for N-67/33), suggesting that dissolved silica from SCSA plays a similar role in the cementing reaction than silicate anions from sodium silicate. Similar trends were observed after 7 days of curing time (Fig. 1b). Interestingly, all SCSA specimens showed better strength results than the control sample after 28 days of curing, mainly for the specimens activated with only sodium hydroxide $(\varepsilon=0)$, which yielded significantly higher compressive strengths than the control

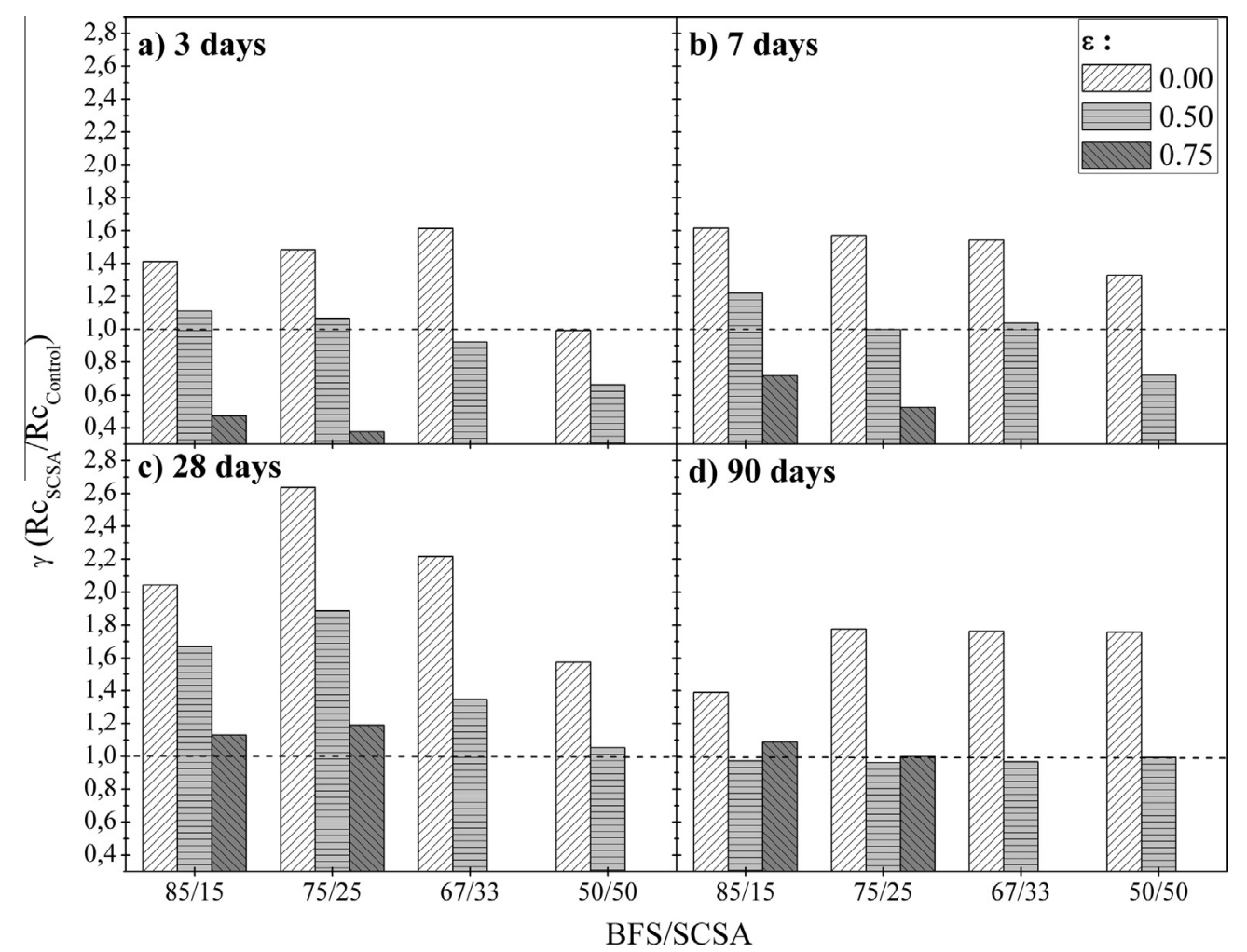

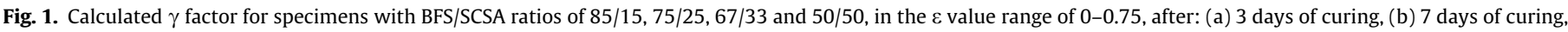
(c) 28 days of curing and (d) 90 days of curing (at $25^{\circ} \mathrm{C}$ ). 


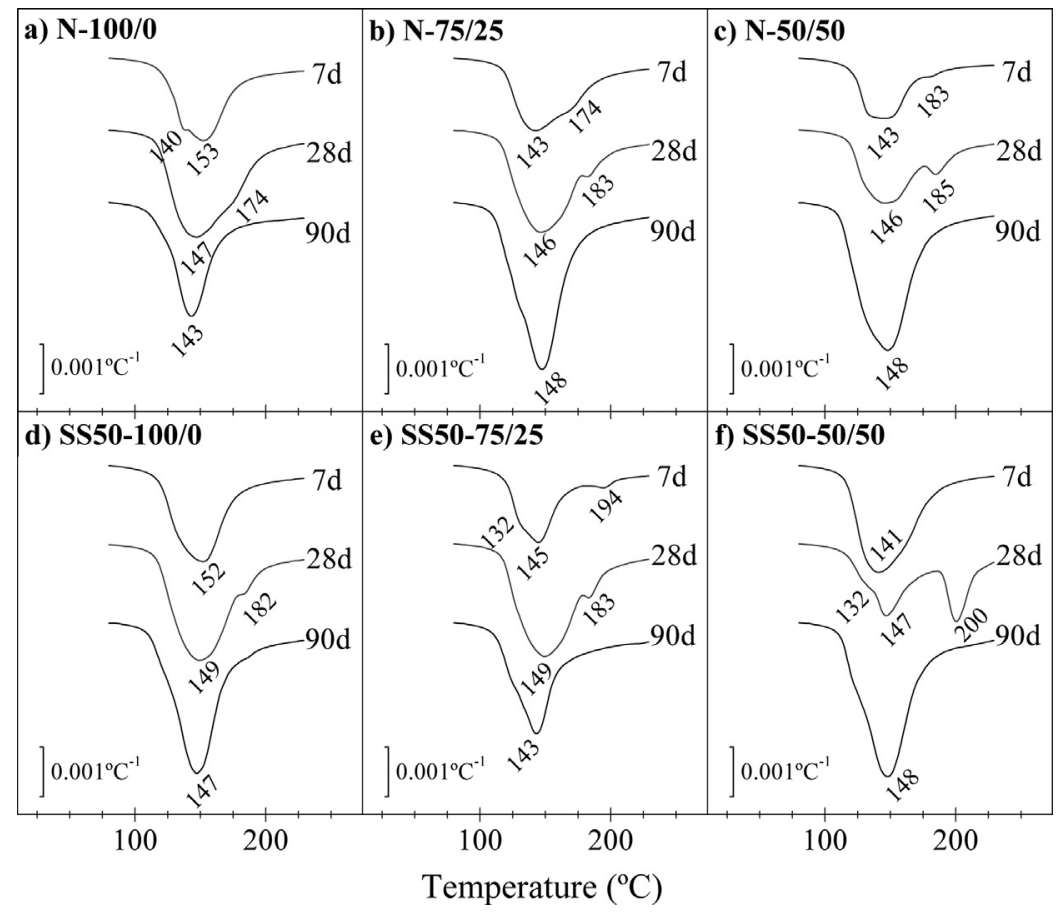

Fig. 2. DTG curves for the N-100/0 (a), SS50-100/0 (b), N-75/25 (c), SS50-75/25 (d), N-50/50 (e) and SS50-50/50 (f) pastes cured for 7,28 and 90 days at $25{ }^{\circ} \mathrm{C}$.

sample. For this curing time, the $\gamma$ factor reached for $\mathrm{N}-75 / 25$ was above 2.5 (Fig. 1c). In contrast to the behavior observed after 3 and 7 days of curing, SCSA mortars with $\varepsilon=0.50$ and $\varepsilon=0.75$ gained important strength: after 28 days of curing, there was a positive effect when silicate anions were incorporated by means of both the alkaline solution and the ash. Thus, the $\gamma$ factor was in the range of 1.67-1.89 for 15-25\% SCSA mortars with $\varepsilon=0.50$, and in the range of $1.13-1.19$ for $15-25 \%$ SCSA samples with $\varepsilon=0.75$ (Fig. 1c). Control mortars (only BFS) significantly increased in strength from 28 to 90 days of curing for all three activating solutions. Despite this, all SCSA containing mortars, after 90 days of curing, yielded similar or higher strength values than the control samples $(\gamma \geqslant 1$, Fig. 1d). Thus, for mortars with $\varepsilon=0$, the $\gamma$ factor values were in the range of 1.39-1.78, confirming the effectivity of the ash in the $\mathrm{NaOH}$-alkali activated BFS mortars. The contribution of silicate anions dissolved from the ash let to 90-day strength values similar to those obtained for BFS mortars with $\varepsilon=0.50-0.75$ (e.g. 48.5 MPa for $\mathrm{N}-75 / 25$ versus 51.2 MPa for SS50-100/0).

In order to assess strength development at higher curing temperatures, a set of mortars was cured at $65^{\circ} \mathrm{C}$. For the studied $\mathrm{BFS}$, the increase in curing temperature did not significantly increase the strength after 3 days of curing; only for the SS75$100 / 0$ specimen was strength development much higher than for the mortar cured at $25^{\circ} \mathrm{C}(27.0 \mathrm{MPa}$ versus $12.8 \mathrm{MPa})$. This behavior means that the presence of an important quantity of silicate anions in the mixture plays a decisive role in enhancing the mechanical properties with a high curing temperature. In an interesting way, for all SCSA containing mortars, the increase in curing temperature led to good strength development and, after 3 days, all samples yielded >20 MPa. Particularly, SS50-75/25 and SS50$67 / 33$ reached $40 \mathrm{MPa}$. This behavior indicates that, at a high curing temperature, the role of SCSA, in terms of strength development, is much more effective than sodium silicate added in the activating solution. Thus, sodium silicate as a chemical reagent could be successfully replaced by SCSA, which also reduced the amount of BFS consumed.

These presented results confirm that is possible to obtain a more sustainable AA binder accordingly the following two factors: the reuse of a biomass waste and the replacement of the sodium silicate solution by an alternative siliceous source. As the biomass became a trend in energy generation in the last years [22], the reuse of these wastes are a form of sustainability. Another issue is the $\mathrm{CO}_{2}$ emission of the sodium silicate production, which is the highest one among the materials used in the AA binders design [15]. Using a less pollutant siliceous source in the place of this activator increases the sustainable characteristic of the AA binder. The similarity in compressive strength of mortars with SCSA ( $\varepsilon$ equal to 0 ) and with only BFS ( $\varepsilon$ equal to 0.50 or 0.75 ) is the confirmation of the improvement in the new designed AA binder in terms of sustainability.

Table 3

Mass losses for the N-100/0, N-75/25, N-50/50, SS50-100/0, SS50-75/25 and SS50-50/ 50 pastes cured for 7,28 and 90 curing days at $25^{\circ} \mathrm{C}$ in defined temperature ranges of TGA:35- $180{ }^{\circ} \mathrm{C}, 180-250{ }^{\circ} \mathrm{C}$ and $250-600^{\circ} \mathrm{C}$.

\begin{tabular}{|c|c|c|c|c|c|}
\hline \multirow{2}{*}{$\begin{array}{l}\text { Curing } \\
\text { time }\end{array}$} & \multirow{2}{*}{$\begin{array}{l}\text { Specimens' } \\
\text { name }\end{array}$} & \multicolumn{4}{|c|}{ Mass loss in a temperature range (\%) } \\
\hline & & $\begin{array}{l}35- \\
180^{\circ} \mathrm{C}\end{array}$ & $\begin{array}{l}180- \\
250^{\circ} \mathrm{C}\end{array}$ & $\begin{array}{l}250- \\
600^{\circ} \mathrm{C}\end{array}$ & TOTAL \\
\hline \multirow{6}{*}{7 days } & $\mathrm{N}-100 / 0$ & 7.61 & 2.47 & 3.52 & 13.60 \\
\hline & $\mathrm{N}-75 / 25$ & 7.56 & 2.44 & 2.92 & 12.92 \\
\hline & $\mathrm{N}-50 / 50$ & 5.67 & 1.58 & 3.35 & 10.60 \\
\hline & SS50-100/0 & 8.27 & 2.33 & 3.29 & 13.89 \\
\hline & SS50-75/25 & 5.95 & 2.10 & 3.89 & 11.94 \\
\hline & SS50-50/50 & 9.78 & 2.24 & 2.72 & 14.74 \\
\hline \multirow[t]{6}{*}{28 days } & $\mathrm{N}-100 / 0$ & 11.15 & 3.41 & 3.75 & 18.31 \\
\hline & $\mathrm{N}-75 / 25$ & 10.41 & 3.34 & 3.83 & 17.58 \\
\hline & $\mathrm{N}-50 / 50$ & 7.39 & 3.35 & 4.54 & 15.28 \\
\hline & SS50-100/0 & 10.75 & 3.28 & 3.77 & 17.80 \\
\hline & SS50-75/25 & 10.22 & 3.36 & 3.91 & 17.49 \\
\hline & SS50-50/50 & 5.75 & 4.66 & 6.67 & 17.08 \\
\hline \multirow[t]{6}{*}{90 days } & $\mathrm{N}-100 / 0$ & 8.89 & 2.85 & 4.51 & 16.25 \\
\hline & $\mathrm{N}-75 / 25$ & 14.22 & 3.07 & 4.37 & 21.66 \\
\hline & $\mathrm{N}-50 / 50$ & 14.25 & 2.92 & 4.15 & 21.32 \\
\hline & SS50-100/0 & 11.63 & 3.19 & 4.65 & 19.47 \\
\hline & SS50-75/25 & 8.46 & 3.18 & 6.62 & 18.26 \\
\hline & SS50-50/50 & 12.43 & 3.24 & 4.87 & 20.54 \\
\hline
\end{tabular}


Fig. 2 shows the DTG curves for $\mathrm{N}-100 / 0, \mathrm{~N}-75 / 25, \mathrm{~N}-50 / 50$, SS50-100/0, SS50-75/25 and SS50-50/50 pastes cured for 7, 28 and 90 days at $25^{\circ} \mathrm{C}$. Table 3 shows the mass losses of these pastes in the temperature intervals of $35-180^{\circ} \mathrm{C}, 180-250^{\circ} \mathrm{C}$ and $250-600^{\circ} \mathrm{C}$. In the DTG curves (Fig. $2 \mathrm{a}-\mathrm{C}$ ), the peaks in the range $140-155^{\circ} \mathrm{C}$ are related to the dehydration of (N,C)-A-S-H gel, whereas the peak at $180-200{ }^{\circ} \mathrm{C}$ can be related to C-A-S-H compounds (e.g. stratlingite, $\mathrm{C}_{2} \mathrm{ASH}_{8}$ ) $[23,24]$. In general terms, the mass loss related to the (N,C)-A-S-H gel increased with the curing age for all mixtures, indicating that the formation of AA products was taking place. The presence of peaks at $180-200^{\circ} \mathrm{C}$ was found after 7 days (small peak or weak shoulder) and 28 days of curing (well-defined peak), and increased with the amount of SCSA in the mixture. After 90 days of curing, the peak related to $\mathrm{C}-\mathrm{A}-\mathrm{S}-\mathrm{H}$ compounds disappeared, and the mass loss in the range of 180$250{ }^{\circ} \mathrm{C}$ decreased (Table 3), indicating that $\mathrm{Na}^{+}$ions cross-linked with this compound and formed a (N,C)-A-S-H gel [25].

In the FTIR spectra (Fig. 3), the main vibration bands of the raw materials and AA pastes are highlighted. First, regarding the raw materials, the main vibration bands of BFS and SCSA were 964 and $1028 \mathrm{~cm}^{-1}$ ( $\mathrm{Si}(\mathrm{Al})-\mathrm{O}-\mathrm{Si}$ vibration), respectively. The pastes showed peaks in the range of $940-980 \mathrm{~cm}^{-1}$ ( $\mathrm{Si}-\mathrm{O}-\mathrm{T}$ vibration, $\mathrm{T}=\mathrm{Si}$ or $\mathrm{Al}$ ) [20]. With an increase in the amount of SCSA in the mixture, the main vibration band shifted to higher wavenumber values. Since the main peak for SCSA has higher wavenumber vibration than the value for BFS, this justifies the higher wavenumber peaks in the pastes with the presence of ash. However, with curing age, the main vibration peak shifted to lower wavenumbers. This behavior is related to the formation of AA products, as shown in the DTG studies.

The XRD patterns of the raw materials (BFS and SCSA) and the $\mathrm{N}-100 / 0$ and $\mathrm{N}-50 / 50$ pastes cured for 28 days at $25^{\circ} \mathrm{C}$ are shown in Fig. 4. Mineralogical analysis showed that SCSA presented quartz (PDF Card \#331161) and calcite (PDF Card \#050586) as the main crystalline phases. The amorphous phase of the ash can be seen in the baseline deviation between the Bragg's angles of $17^{\circ}$ and $33^{\circ}$. BFS showed the typical pattern of an amorphous material by

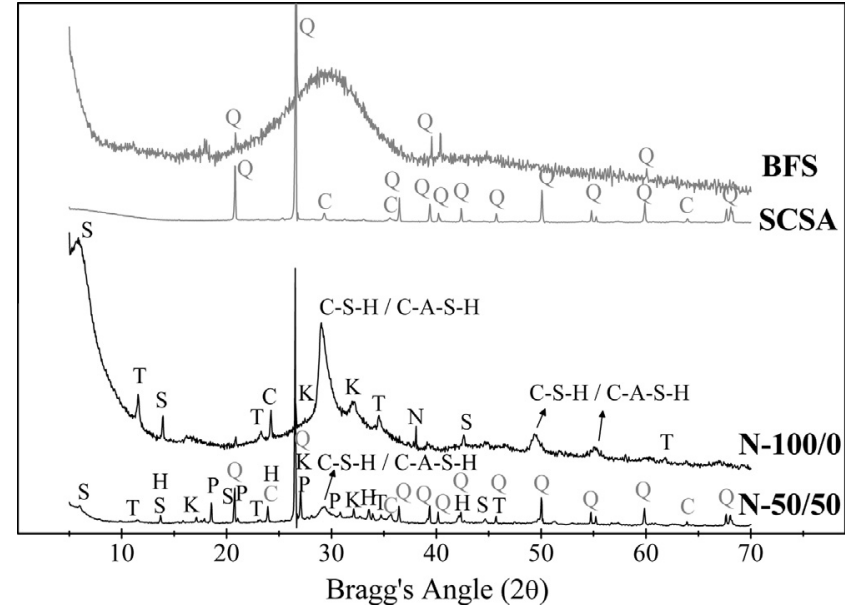

Fig. 4. XRD patterns for the raw materials, BFS and SCSA, and for the $\mathrm{N}-100 / 0$ and $\mathrm{N}-50 / 50$ pastes, cured for 28 days at $25^{\circ} \mathrm{C}$. (Keys: Q: Quartz; C: Calcite; W: Wollastonite; N: Termonatrite; T: Hydrotalcite; K: Katoite; S: Stratlingite; $\mathrm{H}$ : Hydrosodalite; P: Hydrated Nepheline).

presenting a baseline deviation in the range $2 \theta=20-35^{\circ}$. Regarding the pastes, a shift in the baseline deviation range was observed when compared to the raw materials in the $2 \theta$ range between $23^{\circ}$ and $37^{\circ}$. This behavior is typical for the formation of cementing gels $[20,26]$. Another gel formation can be seen by the large peaks of C-S-H and C-A-S-H. Additionally, some crystalline phases were formed: N-100/0 showed peaks of katoite (PDF Card \#380368), stratlingite (PDF Card \#290285) and hydrotalcite (PDF Card \#140191), produced during the activation process $[27,28]$. Termonatrite (PDF Card \#080448) was also observed in the sample, probably due to the carbonation of the sample or transformation of the calcite into a sodium carbonate phase. A slightly different pattern was found for $\mathrm{N}-50 / 50$. In this case, in addition to the previously mentioned phases containing aluminum or silicon, sodium

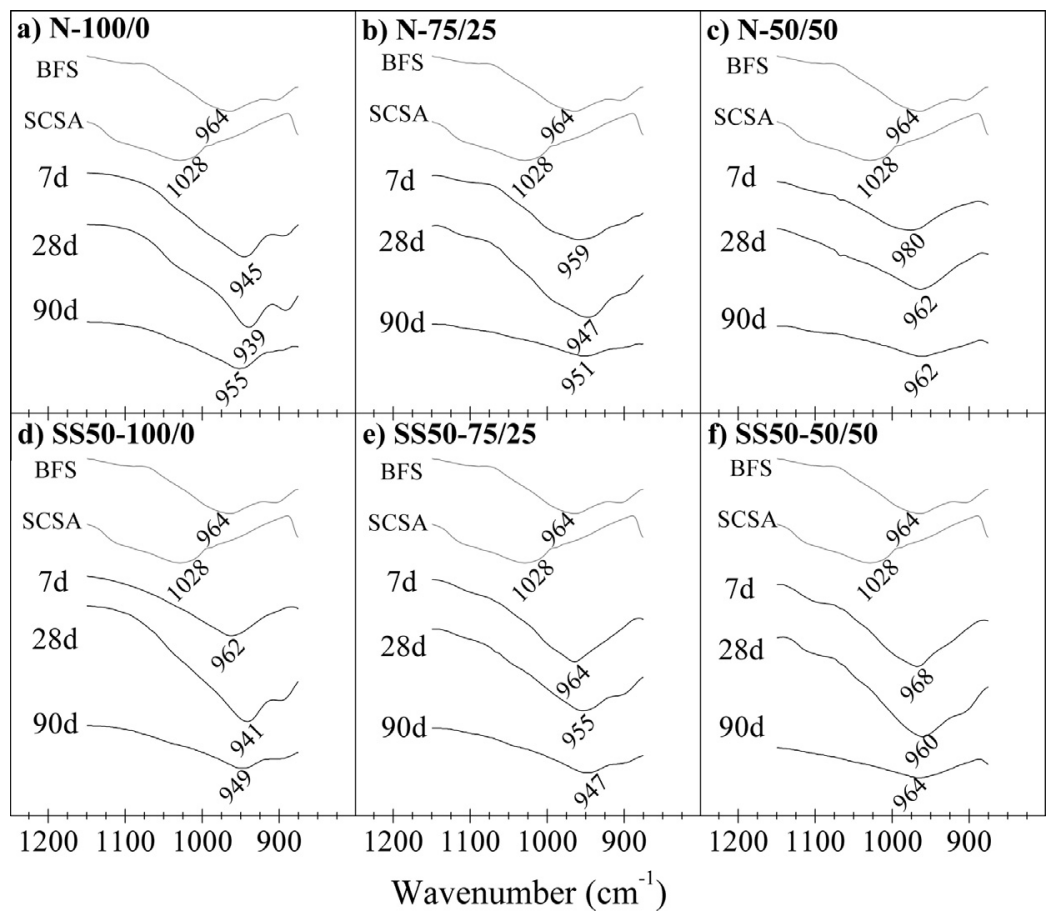

Fig. 3. FTIR spectra for the N-100/0 (a), SS50-100/0 (b), N-75/25 (c), SS50-75/25 (d), N-50/50 (e) and SS50-S50 (f) pastes cured for 7,28 and 90 days at $25{ }^{\circ} \mathrm{C}$. 

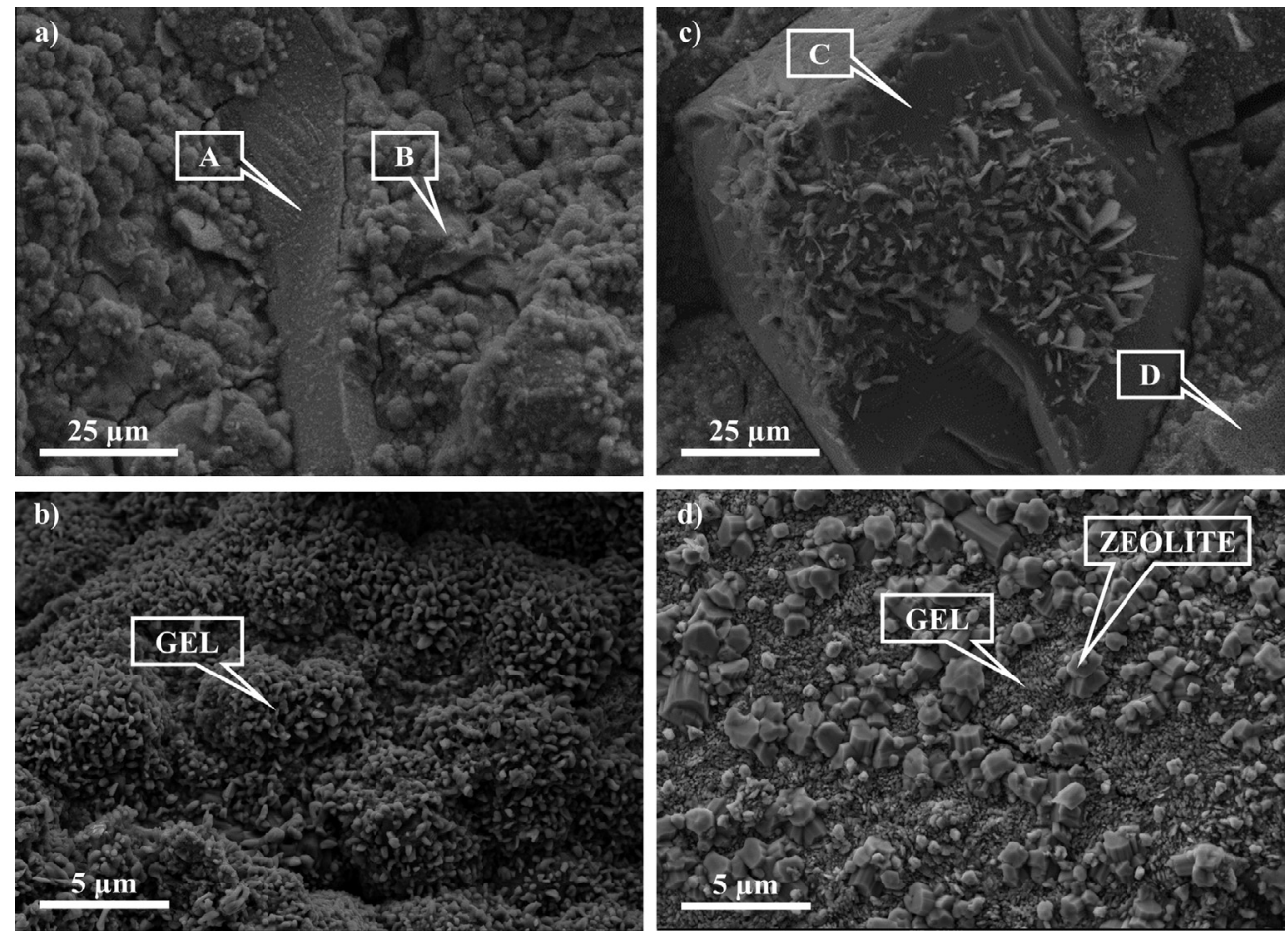

Fig. 5. FESEM images of $\mathrm{N}-100 / 0$ (a and b) and $\mathrm{N}-50 / 50$ (c and d) after 28 days of curing at $25^{\circ} \mathrm{C}$.

zeolite phases were identified, i.e. hydrosodalite (PDF Card \#311271) and hydrated nepheline (PDF Card \#100460). The replacement of BFS by SCSA reduced the $\mathrm{Ca} / \mathrm{Na}$ atomic ratio and increases the $(\mathrm{Si}+\mathrm{Al}) / \mathrm{Na}$ ratio. Consequently, the formation of hydrosodalite and hydrated nepheline was favored.

Fig. 5 shows the FESEM images of the $\mathrm{N}-100 / 0$ (Fig. $5 \mathrm{a}$ and $\mathrm{b}$ ) and $\mathrm{N}-50 / 50$ (Fig. $5 \mathrm{C}$ and d) pastes after 28 days of curing. In Fig. 5a, a reacting BFS particle (Point $\mathrm{A}$ ) and an (N,C)-A-S-H gel (Point $\mathrm{B}$ ) can be seen; the gel had the following molar ratios: $\mathrm{Al} /$ $\mathrm{Si}=0.28 \pm 0.01, \mathrm{Na} / \mathrm{Si}=1.07 \pm 0.05$ and $\mathrm{Ca} / \mathrm{Si}=0.70 \pm 0.05$. In Fig. $5 c$, a quartz particle from SCSA is indicated (Point C), surrounded by an (N,C)-A-S-H gel (Point $\mathrm{D}$ ): this gel presented a higher amount of $\mathrm{Si}$ than that found in the control (molar ratios: $\mathrm{Al} / \mathrm{Si}=0.27 \pm 0.01, \mathrm{Na} / \mathrm{Si}=0.64 \pm 0.01$ and $\mathrm{Ca} / \mathrm{Si}=0.55 \pm 0.09$ ). The presence of SCSA in the mixture favored the formation of gels richer in $\mathrm{Si}$, since the added ash contains silicon as the main metallic element. In a higher magnification (Fig. 5b for N-100/0 and Fig. $5 \mathrm{~d}$ for $\mathrm{N}-50 / 50$ ), it can be seen that the gel of the AA binder with SCSA is more compact than that for the control one, which also can justify the best performance in the compressive strength test. In addition, zeolite crystals formation in the N-50/50 sample can be observed (Fig. 5d).

\section{Conclusions}

The reactivity of SCSA in BFS-based alkali activated binders offers huge advantages. A sustainable material was obtained in this study. First, the replacement of BFS (15-50\% by mass) by SCSA in $\mathrm{NaOH}$ activated systems provided excellent mechanical properties in the mortar, and similar or higher strengths than BFS systems (without SCSA) activated by $\mathrm{NaOH} /$ sodium silicate mixtures were achieved. Secondly, the use of SCSA reduced the use of the most expensive chemical reagent in these activated systems, i.e. sodium silicate. Finally, a high degree of valorization for these ashes was achieved by using them in this type of binder, and offers an interesting solution for managing sugar cane straw wastes. In summary, more sustainability was achieved by replacing BFS and sodium silicate in the design of new binders, and by the proposal of a new valorization method for sugar cane straw waste.

\section{Acknowledgment}

The authors would like to thanks to CNPq processo no. 401724/2013-1 and the "Ministerio de Educación, Cultura y Deporte" of Spain ("Cooperación Interuniversitaria" program with Brazil PHB-2011-0016-PC). Thanks are also given to the Electron Microscopy Service of the Universitat Politècnica de València.

\section{References}

[1] J.W. Phair, Green chemistry for sustainable cement production and use, Green Chem. 8 (2006) 763-780.

[2] H. Rostami, W. Brendley, Alkali ash material: a novel fly ash-based cement, Environ. Sci. Technol. 37 (2003) 3454-3457.

[3] C. Kuenzel, T.P. Neville, S. Donatello, L. Vandeperre, A.R. Boccaccini, C.R. Cheeseman, Influence of metakaolin characteristics on the mechanical properties of geopolymers, Appl. Clay Sci. 83-84 (2013) 308-314.

[4] V. Nikolic, M. Komljenovic, Z. Bašcarevic, N. Marjanovic, Z. Miladinovic, R. Petrovic, The influence of fly ash characteristics and reaction conditions on strength and structure of geopolymers, Constr. Build. Mater. 94 (2015) 361370.

[5] N.R. Rakhimova, R.Z. Rakhimov, Alkali-activated cements and mortars based on blast furnace slag and red clay brick waste, Mater. Des. 85 (2015) 321-331.

[6] J. Davidovits, Environmentally driven geopolymer cement applications, in: Geopolymer International Conference, 2002.

[7] B. McLellan, R. Williams, J. Lay, A. Van Riessen, G. Corder, Costs and carbon emissions for geopolymer pastes in comparison to ordinary Portland cement, J. Clean. Prod. 19 (2011) 1080-1090.

[8] J. Davidovits, Geopolymer Chemistry and Applications, 3rd ed., Institut Géopolymère, France, 2001.

[9] J.M. Mejía, R.M. Gutiérrez, C. Montes, Rice husk ash and spent diatomaceous earth as a source of silica to fabricate a geopolymeric binary binder, J. Clean. Prod. 118 (2016) 113-139.

[10] E. Nimwinya, W. Arjharn, S. Horpibulsuk, T. Phoo-ngernkham, A. Poowancum, A sustainable calcined water treatment sludge and rice husk ash geopolymer, J. Clean. Prod. 119 (2016) 128-134.

[11] S.D. Wang, X.C. Pu, K.L. Scrivener, P.L. Pratt, Alkali-activated slag cement and concrete: a review of properties and problems, Adv. Cem. Res. 7 (1995) 93102. 
[12] N.R. Rakhimova, R.Z. Rakhimov, A review on alkali-activated slag cements incorporated with supplementary materials, J. Sustainable Cem. Mater. 1 (2014) 61-74.

[13] R. Martinez-Lopez, J.I. Escarlate-Garcia, Alkali activated composite binders of waste silica soda lime glass and blast furnace slag: strength as a function of the composition, Constr. Build. Mater. 119 (2016) 119-129.

[14] C. Meyer, The greening of the concrete industry, Cem. Concr. Compos. 31 (2009) 601-605.

[15] A. Mellado, C. Catalán, N. Bouzón, M.V. Borrachero, J.M. Monzó, J. Payá, RSC Adv. 4 (2014) 23846

[16] N. Bouzón, J. Payá, M.V. Borrachero, L. Soriano, M.M. Tashima, J. Monzó, Refluxed rice husk ash/NaOH suspension for preparing alkali activated binders, Mater. Lett. (2014) 72-74.

[17] Sugarcane production. UNICA - União da Indústria de Cana-de-Açúcar Website; <http://www.unicadata.com.br/index.php?idioma=2>

[18] M.R.L.V. Leal, M.V. Galdos, F.V. Scarpare, J.E.A. Seabra, A. Walter, C.O.F. Oliveira, Sugarcane straw availability, quality, recovery and energy use: a literature review, Biomass Bioenergy 53 (2013) 11-19.

[19] J.C.B. Moraes, J.L. Akasaki, J.L.P. Melges, J. Monzó, M.V. Borrachero, L. Soriano, J. Payá, M.M. Tashima, Assessment of sugar cane straw ash (SCSA) as pozzolanic material in blended Portland cement: Microstructural characterization of pastes and mechanical strength of mortars, Constr. Build. Mater. 94 (2015) 670-677.

[20] A. Pereira, J.L. Akasaki, J.L.P. Melges, M.M. Tashima, L. Soriano, M.V. Borrachero, J. Monzó, J. Payá, Mechanical and durability properties of alkali-activated mortar based on sugarcane bagasse ash and blast furnace slag, Ceram. Int. 41 (2015) 13012-13024.

[21] V.N. Castaldelli, J.L. Akasaki, J.L.P. Melges, M.M. Tashima, L. Soriano, M.V Borrachero, J. Monzó, J. Payá, Use of slag/sugar cane bagasse ash (SCBA) blends in the production of alkali-activated materials, Materials 6 (2013) 3108-3127.

[22] W.H. Chen, J. Peng, X.T. Bi, A state-of-the-art review of biomass torrefaction, densification and applications, Renewable Sustainable Energy Rev. 44 (2015) 847-866.

[23] M. Palou, J. Majling, M. Dovái, J. Kozankivá, S.B. Mojmdar, Formation and stability of crystallohydrates in the non-equilibrium system during hydration of sab cements, Ceram. Silikáty 49 (2005) 230-236.

[24] W. Chen, H.J.H. Brouwers, The hydration of slag, part 1: reaction models for alkali-activated slag, J. Mater. Sci. 42 (2007) 428-443.

[25] J.L. Provis, A. Palomo, C. Shi, Advances in understanding alkali-activated materials, Cem. Concr. Res. 78 (2015) 110-125.

[26] J.L. Provis, G.C. Lukey, J.S.J. van Deventer, Do geopolymers actually contain nanocrystalline zeolites? A reexamination of existing results, Chem. Mater. 17 (2005) 3075-3085.

27] J.L. Provis, S.A. Bernal, Geopolymers and related alkali-activated materials, Annu. Rev. Mater. Res. 44 (2014) 299-327.

[28] F. Puertas, A. Fernández-Jiménez, M.T. Blanco-Varela, Pore solution in alkaliactivated slag cement pastes. Relation to the composition and structure of calcium silicate hydrate, Cem. Concr. Res. 34 (2004) 139-148. 